\title{
Does Age Have Different Influence between Mountain and City Marathons? - An Analysis from Switzerland
}

\author{
Benedikt Gasser* \\ University of Berne, Switzerland
}

*Corresponding author: Benedikt Gasser, University of Berne, Zellmoosweg 33, 6210 Sursee, Switzerland

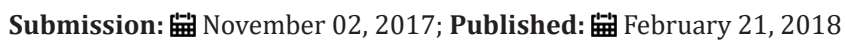

\begin{abstract}
Aging results in decreasing physical capabilities. Different organ systems with high relevance for endurance capacity underlie changes whereby especially cardiovascular, pulmonary, skeletal muscle and endocrine system can be mentioned. That these biological constraints yield to an optimal age for middle distances in running with around 20 to 30 years is generally known and the fact that longer distances such as marathons or ultra-races have a higher optimal age around 40 is generally accepted. Little evidence exists concerning the interaction between age and topography of a course (flat versus mountainous). When comparing for double starters running times in Napfmarathon (in a mountainous region in the heart of Switzerland) with City marathons of Zürich, Lausanne, Winterthur and Lucerne from 2011-2016 optimal age for runners were in both races around 35 years. Furthermore, the decrease in age-associated performance was smaller in Napfmarathon compared to City Marathons. This is probably due to a total higher work load in Napfmarathon as a result of height difference. This is supported by the fact that optimal age increases with increase of total amount of performance. Furthermore, in mountain courses a higher share of eccentric muscle work is probably necessary especially in downhill running what might explain the smaller association between age and mountain marathons. Further, elasticity of collagen structures such as ligaments or tendons which degenerate during aging may play an important role. In flat courses such as city marathons where proper running movement is possible a higher workload can be performed with these structures. From a performance point of view, it is likely to suppose that with special training such as stretching; Black Roll or Jump Training collagen associated performance can be preserved or even improved while aging.
\end{abstract}

Keywords: Age; Performance capacity; Topography; Marathon; Mountain marathon

\section{Introduction}

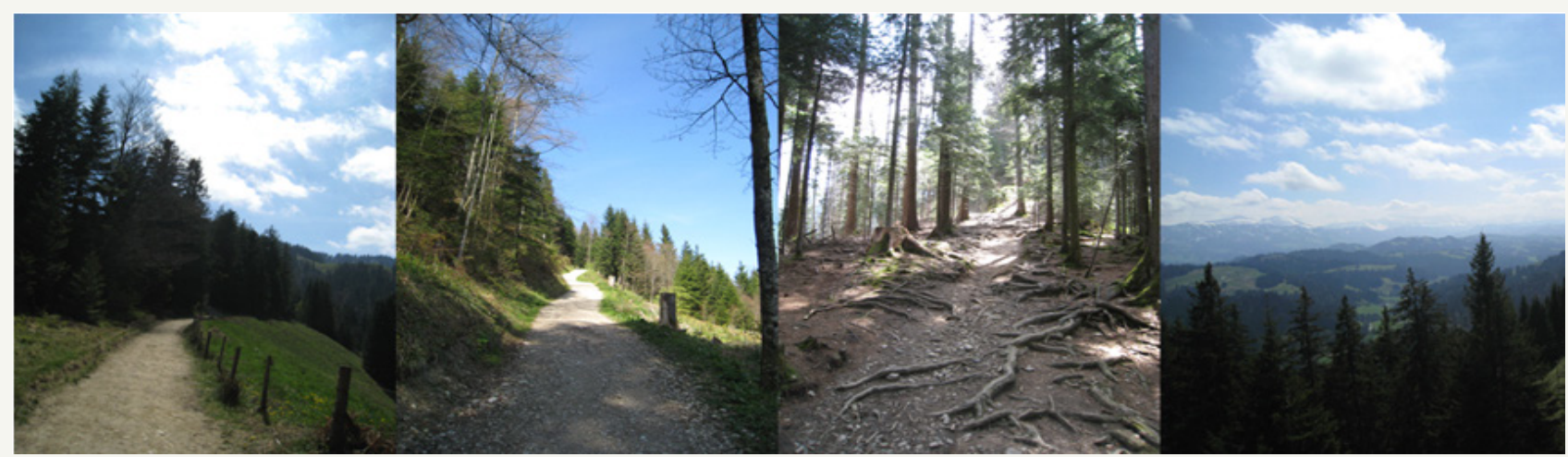

Figure 1: Natural streets, deep ascents and descents as well as challenging forest trails are signs of running in Napf area in the heart of Switzerland.

With increasing age a decrease in endurance capacity results [1]. This counts for different organ systems such as heart, lung, skeletal muscle or endocrine system on different structural and functional level [1-4]. Studies tax the decrease of endurance capacity after the 30 . Year of life with $15 \%$ per decade to keep in mind with increasing distance the optimum of maximum distance is based on adaptations while years through training higher [58]. The detected optimal age for middle distances is between 20 and 30 years, for marathon races around 35 years and increases to 40 or more years for ultra-races [8-11]. Addressing changes in general endurance performance in leisure sports men for marathon running analysis of the big sample of over $9000^{`} 000$ course times revealed that for 20- to 79-year old marathon and half-marathon runners that interestingly no significant decrease based solely on age could be detected respectively decrease was mainly a result of physical inactivity [1]. Physical activity seems to hinder aging and has protective potentials for many illnesses [11-14]. Hints exist, that especially endurance sports respectively running 
has preventive potential due to the fact that this kind of activity was developed by our ancestors in the hunter and gatherer time during the development of Homo yielding to a divergence between chimpanzee and human [11-16]. The astonishing evolutionary fact is to mention that hunter and gatherer were running in average 9 to $15 \mathrm{~km}$ per day and in contrast to often proclaimed these ancestors lived-when surviving the first years of life - long and healthy lives of 70 and more years $[17,18]$. Depending on running and gait pattern biological requirements are differing and requirements on cardiopulmonary and musculoskeletal system change, whereby smallest changes such as shoe influences gait pattern and secondary cardiopulmonary system [3,14-16](Figure 1). Especially uphill running in mountainous terrain compared to other forms (e.g. track and field or street running) is characterized through different biomechanical patterns underlying different age associated changes $[19,20]$. This yields to the central question of the study whether with increasing age differences in age associated decrease in performance can be detected in mountain versus city marathons. Is the optimal age depending on terrain flat versus mountainous different? As hypothesis with potential possibility of falsification it is postulated, that there is no difference in optimal age between city and Mountain marathon [21].

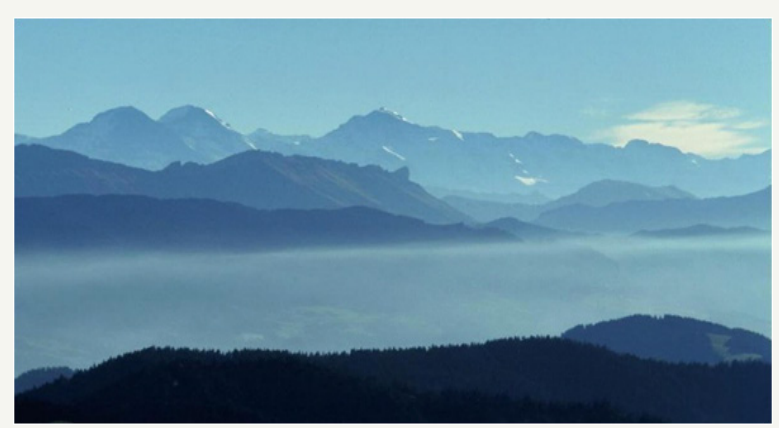

Figure 1b: View from Napf to the Berner Alpen with Eiger, Mönch and Jungfrau.

\section{Material \& Methods}

\section{Procedures}

For analyzing the effect of age on course times all runners participating in the years 2011-2016 on Napfmarathon in central Switzerland were analyzed. Total sample counted 995 runners, 205 female and 790 male runners. Share of woman was $20.6 \%$ representing a typical pattern for mountain- and ultramarathon races [22]. To compare course times all participants were screened for double starts for flat respectively city marathons in Zürich, Winterthur, Lausanne and Lucerne. The sample consisted of 63 male double starters (49.8 \pm 9.1 years) and 4 female double starters (43.3 \pm 8 .8 years) participating in the analyzed time from 2011-2015 at Napfmarathon and in the same year in a city marathon in Zürich (36 runners), in Winterthur (19 runners), in Lausanne (2 runners) or in Lucerne (10 runners). Resulting in 13 double participation in 2011, 20 double participation in 2012, 8 double participation in 2013, 13 double participation in 2014 and 13 double participation in 2015 .

\section{The race-course description}

Starting in Trubschachen (731 Meter above Sea Level) on asphalt streets and then mainly on small trails to Risisegg, Schaffmatt, Altengrat, Chrützboden, Schwesternboden to Napf (1408 Meter above sea level). Descent is on west side to Niederänzi, Höchänzi, Lushütte, Hohmatt, Schynen, Bachschwand back to Trubschachen. Total race is $41.98 \mathrm{~km}$ with an ascent and descent of 1270 Meters.

\section{Statistical procedures}

For each year 2011-2016 means and standard deviation of course times were calculated. To analyze relationship between course time and age linear regressions were conducted. Furthermore, polynomial interpolation of 2 degree were calculated, yielding through differentiation to the local minimum [22-27]. To analyze effects of total performance with additional ascent and descent of 1270 meters analyzes were conducted with the concept of performance $\mathrm{km}$ [28]. Differences of course times between city marathons and Napfmarathon were analyzed with two-sided paired t-tests.

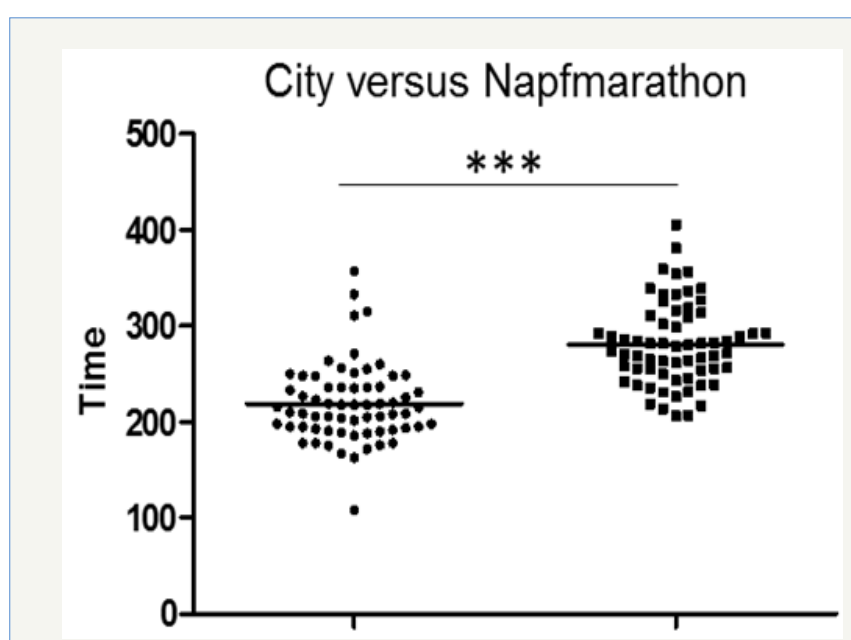

Figure 2: Course times for the matched sample left for the city marathons and right for the Napfmarathon. Differences in course times are highly significant $(p<0.01)$.

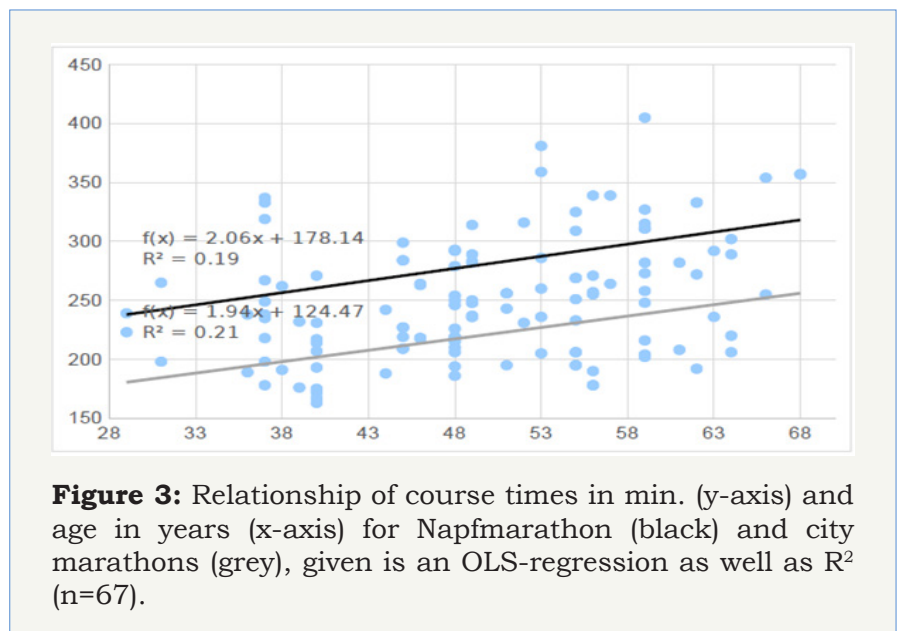

Figure 2 shows all course times of the matched sample for city marathon with an average course time of $3 \mathrm{~h} 39 \pm 41 \mathrm{~min}$ and right 
for Napfmarathon with $4 \mathrm{~h} 40 \pm 43 \mathrm{~min}$. Average age of the matched sample was $49.8 \pm 9.1$ years representing a typical senior cohort (Figure 3).

The analyzed polynomial Interpolation 2 Degree for the matched sample yielding to an u-shaped age course time relationship with optimal age of 34 years in Napfmarathon and 35 years in city marathons (Figure 4), whereby these findings are supported by others [24].
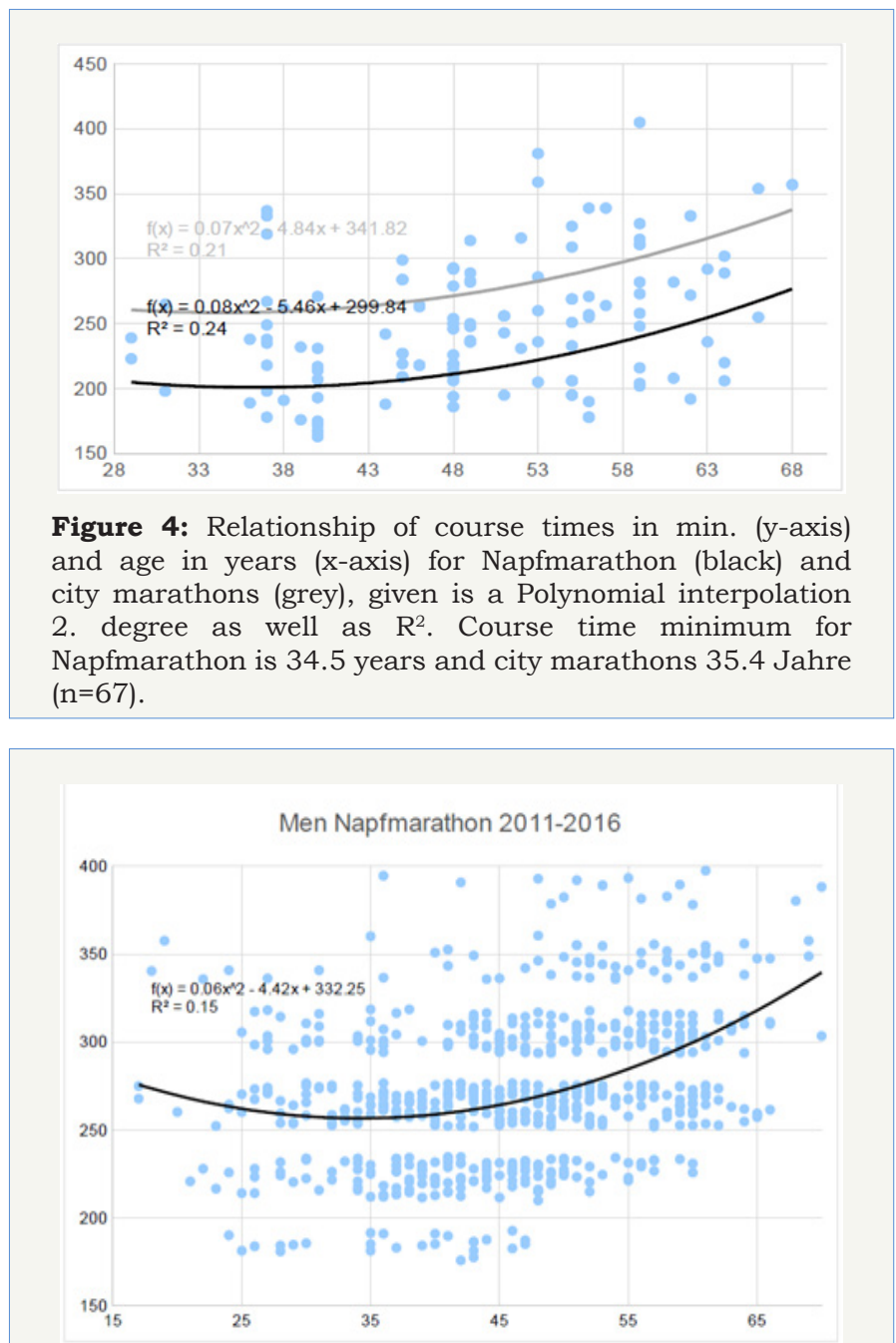

Figure 5: Men 2011-2016 polynomial interpolation 2. Degree for all runners of Napfmarathon-minimum course time was detected with 34.2 years $(n=699)$.

If all course times are taken, local minimum for men is around 34 years nearly equivalent for both competitions forms (Figure 5). In woman with 28.7 years a lower value results a pattern also found for Jungfraumarathon where reasons were attributed towards differences in lean mass [22,24-27](Figure 6). Trying to compare results from statistical regressions, with $\beta=1.7$ for Napfmarathon versus $\beta=2.1$ for city marathon a smaller increase in course times results with increasing age (Figure 3) Furthermore, R2=0.15 for Napfmarathon is smaller than R2=0.19 for city marathons (Figure 3 ). Trying to analyze effect of absolute performance (considering height differences in Napfmarathon) to control, concept of performance $\mathrm{km}$, whereby 100 Meter Ascent and $1 \mathrm{~km}$ horizontal distance are equivalents [28]. For the matched sample for city marathon an average $\mathrm{km}$ of $5 \mathrm{~min} 14 \mathrm{sec} \pm 55 \mathrm{sec}$ and for Napfmarathon quantified with performance concept $5 \mathrm{~min} 1 \mathrm{sec} \pm 46 \mathrm{sec}$ result. Furthermore, analyses reveal in Figure 7, that Napfmarathon with a regression weight of $\beta=0.0369$ is smaller than in city marathon with $\beta=0.0487$, in line with the before mentioned and implying, that the decrease in physical endurance performance in Napf marathon is smaller compared to city marathons. Besides other reasons the simple fact of the total larger amount of performance is probably one important reason $[3,7,8,11,22]$. The meter above sea level of the race (700 to 1400 Meter) respectively the effect of a smaller oxygen pressure doesn't seem to be relevant while analyzing differences (e.g. City marathon in Lucerne took place around 500 meters above sea level) [29].

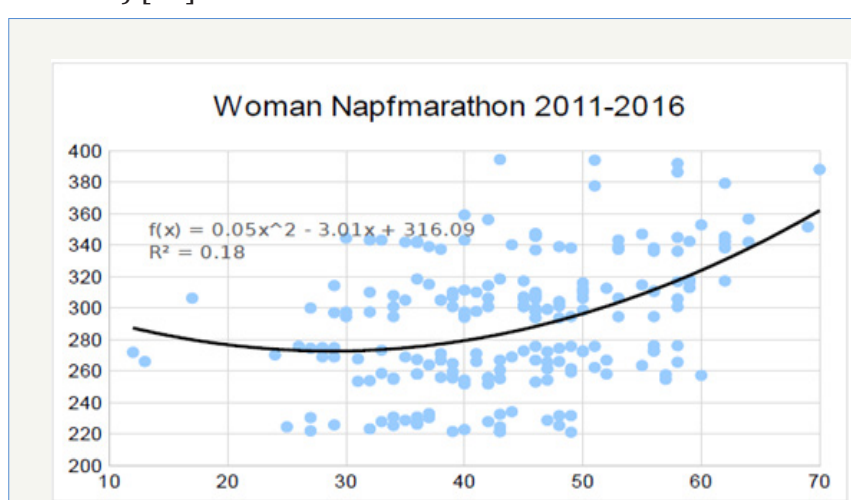

Figure 6: Frauen 2011-2016 polynomial interpolation 2. Degree for all female runners in Napfmarathon-minimum results with 28.7 years $(n=205)$.

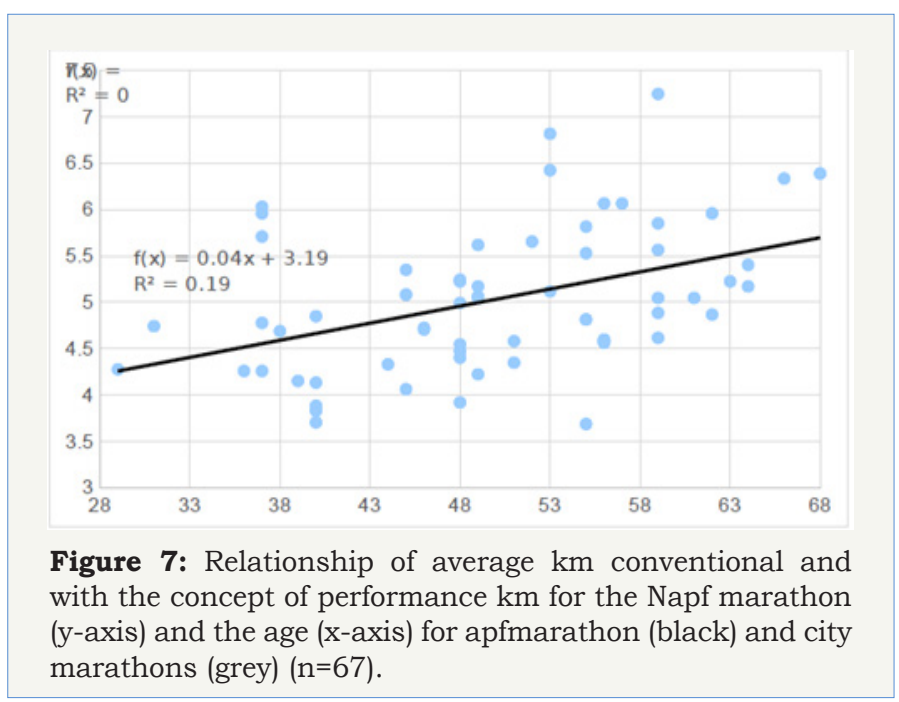

\section{Discussion}

The aim of this study was to compare different effects of age on course times in mountain and city marathons. Recently result lists from marathon races were used as epidemiological data allowing analyzing large samples and age associated alterations of performance [1]. Encompassing analyses of city marathons (e.g cologne Marathon with more than 900`000 course times or 
Stockholm marathons with more than $300 ` 000$ course times can be mentioned $[1,26]$. For mountain marathons in Switzerland especially the analysis from the Jungfrau Marathon can be mentioned. The advantage of these studies is the large analyzed samples with potential high validity of findings [25]. However, for limitations of possible statistical analyses a matching of course times is not yet possible, making the analyzes despite the small sample interesting. On the search for reasons for differences variance is reduced as a consequence of paired samples however limitations are given based on a sample size. It must be considered that leisure sportsmen were analyzed having strongly different training habits with comparable performance $[3,8]$. This thought is supported by an analysis of the Jungfrau Marathon whereby results of best classed runner versus the whole sample where analyzed concerning optimal age [25]. Average course times were with around one hour more clearly higher in Napfmarathon compared to city marathon. This is probably due to the fact, that the absolved height of 1200 Meters. Given the concept of performance km additional 12 performance $\mathrm{km}$ had to be absolved yielding to an average performance $\mathrm{km}$ of 5 Minutes. This seems to be a little bit low however when comparing with other concepts of distance and height the performance equivalent of 100 Meter ascents seems to be a little bit less than $1 \mathrm{~km}$ horizontal distance [30,31]. Analyses reveal that from the age of 35 a decrease in performance capacity results, which is in accordance with a number of other studies $[2-7,32,33]$. Trying to decipher reasons for the age associated decrease in endurance capacity besides the mentioned decrease in cardio-pulmonary system especially collagen tissue-ligaments and tendons-can be mentioned [34,35]. Furthermore, skeletal muscle is characterized through different contraction forms (arbitrary) concentric versus eccentric and besides other factors in dependence of a course is differently used dependent on topography $[3,35,36]$. When running downhill eccentric (breaking) muscle work must be conducted, having especially relevance for the second part of the race of Napfmarathon possible to combine with the results [37-39]. Furthermore, Analysis reveal a closer relationship between age and course times in city marathons versus Napfmarathon. Coming to reasons the higher total amount of performance in Napfmarathon is to mention, whereby results are in accordance that with increasing age performance for longer distances is better. Furthermore, in contrast to Jung fraumarathon the whole Height has to be made downhill (relevance of eccentric muscle activity) [25]. The analyzed optimal age is for both forms around 35 years and is in accordance with younger studies also detecting a U-shaped relationship (polynomial interpolation of 4. Degree) between age and Marathon time and course time minimum was around 35 years [25].

Trying to decipher the smaller explanation of variance between age and Napfmarathon versus city marathon it seems efficient to come back to the cardio-pulmonary system respectively the decrease in endurance sports of maximal oxygen consumption (VO2max), already decreasing after the age of 20 and secondary affecting cardiopulmonary system [2-6]. This explains the increase of course times with increasing age but not the principally closer correlative relationship between age and city marathon versus age and Napfmarathon. This might be a result of the mentioned fact of a higher share of eccentric muscle activity in Napfmarathon while running downhill, where $\mathrm{VO}_{2 \max }$ is less relevant [37-39]. Eccentric muscle activity has other cardiopulmonary restrictions than concentric, respectively with increasing muscle activity a smaller increase of Oxygen consumption while increasing performance results probably relevant for the smaller association of age and course times in Napfmarathon [40].

Furthermore, associated structures of collagen tissue (tendons and ligaments) are to mention which lose elasticity with increasing age [19,40-42]. For a mountain marathon, the decrease in elasticity could have smaller consequences, due to the fact that in downhill running elasticity of tendons are less important than when running in the flat with the importance of storage of (elastic) energy [40]. The mentioned premise is supported that in collagen tissue alterations of matric proteins and proteoglykans with reduced plasticity and elasticity of ligaments and tendons with increased stiffness result [40-42]. Training of these structures could lead to an improvement of age-associated decrease and improve general performance of seniors [36,43].

\section{Acknowledgments}

A special thanks goes to Roland Schütz for the constructive hints concerning physiological requirements for mountain marathons.

\section{References}

1. Leyk D, Rüther T, Wunderlich M, Sievert A, Essfeld D, et al. (2010) Physical performance in middle age and old age: good news for our sedentary and aging society. Dtsch Arztebl Int 107(46): 809-816.

2. Ferrari AU, Radaelli A, Centola M (2003) Invited review: aging and the cardiovascular system. J Appl Physiol 95(6): 2591-2597.

3. Zintl F, Eisenhut A (2009) Ausdauertraining: Grundlagen, Methoden, Trainingssteuerung. BLV Buchverlag, München, Germany.

4. Jackson AS, Beard EF, Wier LT, Ross RM, Stuteville JE, et al. (1995) Changes in aerobic power of men, ages 25-70 yr. Med Sci Sports Exerc 27(1):113-120

5. Stathokostas L, Jacob-Johnson S, Petrella RJ, Paterson DH (2004) Longitudinal changes in aerobic power in older men and women. J Appl Physiol 97(2): 784-749.

6. Hollenberg M, Yang J, Haight TJ, Tager IB (2006) Longitudinal changes in aerobic capacity: implications for concepts of aging. J Gerontol A Biol Sci Med Sci 61(8): 851-858.

7. Romer T, Rüst CA, Zingg MA, Rosemann T, Knechtle B (2014) Age and ultra-marathon performance-50 to 1,000km distances from 1969-2012. SpringerPlus 3:693.

8. Steffny H (2010) Optimales lauftraining. Südwestverlag, München, Germany.

9. Knechtle B, Nikolaidis PT (2017) The age of the best ultramarathon performance-the case of the "Comrades Marathon". Res Sports Med 25(2): $1-12$

10. Knechtle B, Assadi H, Lepers H, Rosenmann T, Rüst CA (2014) Relationship between age and elite marathon race time in world single age records from 5 to 93 years. BMC Sports Sci Med Rehabil 6: 31.

11. Borghini A, Giardini G, Tonacci A, Mastorci F, Mercuri A, et al. (2015) Chronic and acute effects of endurance training on telomere length. Mutagenesis 30(5): 711-716. 
12. Lieberman D (2015) Is Exercise Really Medicine? An Evolutionary Perspective. Curr Sports Med Rep 14(4): 313-319.

13. Lieberman DE, Venkadesan M, Werbel WA, Daoud AI, D’Andrea S, et al. (2010) Foot strike patterns and collision forces in habitually barefoot versus shod runners. Nature 463(7280): 531-535

14. Heglund NC, Taylor CR (1988) Speed, stride frequency and energy cost per stride. How do they change with body size and gait? J Exp Biol 138: 301-318.

15. Bramble DM, Lieberman DE (2004) Endurance running and the evolution of Homo. Nature 432(7015): 345-352.

16. Marlowe FW (2010) The Hadza: Hunter-Gatherers of Tanzania University of California Press, Berkeley (CA), p. 325.

17. Blurton Jones NG, Smith LC, O’Connell JF, Hawkes K, Kamuzora CL (1992) Demography of the Hadza, an increasing and high density population of Savanna foragers. Am J Phys Anthropol 89(2): 159-181.

18. Giovanelli N, Taboga P, Rejc E, Simunic B, Antonutto G, et al. (2016) Effects of an uphill marathon on running mechanics and lower-limb muscle fatigue. Int J Sports Physiol Perform 11(4): 522-529.

19. Burtscher M, Förster H, Burtscher J (2008) Superior endurance performance in aging mountain runners. J Gerontol 54(5): 268-271.

20. Popper KR (1969) Logik der Forschung. Mohr Siebeck, Tübingen, Germany.

21. Knechtle B, Valeri F, Zingg MA, Rosemann T, Rüst CA (2014) What is the age for the fastest ultra-marathon performance in time-limited races from 6 h to 10 days? Age (Dordr) 36(5): 9715.

22. Reinboud W (2004) Linear models can't keep up with sport gender gap. Nature 432(7014): 147.

23. Lara B, Salinero JJ, Del Coso J (2014) The relationship between age and running time in elite marathoners is U-shaped. Age (Dordr) 36(2): 10031008.

24. Knechtle B, Rosemann T, Zingg MA, Rüst CA (2015) Increase in participation but decrease in performance in age group mountain marathoners in the 'Jungfrau Marathon': a Swiss phenomenon? Springerplus 4: 523.

25. Lehto N (2016) Effects of age on marathon finishing time among male amateur runners in Stockholm Marathon 1979-2014. J Sport Health Sci 5(3): 349-354.

26. Barandun U, Knechtle B, Knechtle P, Klipstein A, Rüst, CA, et al. (2012) Running speed during training and percent body fat predict race time in recreational male marathoners. Open Access J Sports Med 3: 51-58.

27. Winkler K, Brehm HP, Haltmeier J (2008) Bergsport Sommer. Bern.

28. Bailey DM, Davies B, Romer L, Castell L, Newsholme E, et al. (1998)

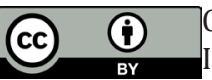

reative Commons Attribution 4.0

nternational License

For possible submissions Click Here
Implications of moderate altitude training for sea-level endurance in elite distance runners. Eur J Appl Physiol Occup Physiol 78(4): 360-368.

29. Scarf P (2007) Route choice in mountain navigation, Naismith's rule, and the equivalence of distance and climb. J Sports Sci 25(6): 719-726.

30. Langmuir E (1984) Mountaincraft and Leadership. Official Handbook of the Mountain Leader Training Boards of Great Britain and Northern Ireland. Britain \& Scottish Sports Council, Edinburgh Scotland.

31. Trappe S (2007) Marathon runners: how do they age? Sports Med 37(45): 302-305.

32. Eichenberger E, Knechtle B, Rüst CA, Rosemann T, Lepers R (2012) Age and gender interactions in mountain ultra-marathon running - the 'Swiss Alpine Marathon'. Open Access J Sports Med 3: 73-80.

33. Svensson RB, Heinemeier KM, Couppe C, Kjaer M, Magnusson SP (2016) The effect of aging and exercise on the tendon. J Appl Physiol 121(6): 1237-1246.

34. Fukashiro S, Hay DC, Nagano A (2006) Biomechanical behavior of muscle-tendon complex during dynamic human movements. J Appl Biomech 22(2):131-147.

35. Hughes SM, Schiffiano S (1999) Control of muscle fibre size: a crucial factor in ageing. Acta Physiol Scand 167(4): 307-312.

36. Vogt M, Hoppeler HH (2014) Eccentric exercise: mechanisms and effects when used as training regime or training adjunct. J Appl Physiol 116(11): 1446-1454

37. Vogt M, Däpp C, Blatter J, Weisskopf R, Suter G, et al. (2003) Training zur Optimierung der Dosierung exzentrischer Muskelaktivität. Schweizerische Zeitschrift für Sportmedizin und Sporttraumatologie 51(4): 188-191

38. Vogt M (2007) Exzentrisches Training.

39. Vallejo AF, Schroeder ET, Zheng L, Jensky NE, Sattler FR (2006) Cardiopulmonary responses to eccentric and concentric resistance exercise in older adults. Age Ageing 35(3): 291-297.

40. Alexander RM, Bennet-Clark HC (1977) Storage of elastic strain energy in muscle and other tissues. Nature 265(5590): 114-117.

41. Kim JS, Lee YH, Yi HK (2016) Gradual downhill running improves agerelated skeletal muscle and bone weakness: implication of autophagy and bone morphogenetic proteins. Exp Physiol 101(12): 1528-1540.

42. Brüggemann GP (2000) Speicherung und Nutzung elastischer Energie in Sehnen und Bändern der unteren Extremität bei hochdynamischen Absprüngen im Sport. BISp-Jahrbuch. Deutsche Sporthochschule Köln Institut für Biomechanik.

43. Gluchowski A, Harris N, Dulson D, Cronin J (2015) Chronic Eccentric Exercise and the Older Adult. Sports Med 45(10): 1413-1430.

\section{Your subsequent submission with Crimson Publishers will attain the below benefits}

- High-level peer review and editorial services

- Freely accessible online immediately upon publication

- Authors retain the copyright to their work

- Licensing it under a Creative Commons license

- Visibility through different online platforms

- Global attainment for your research

- Article availability in different formats (Pdf, E-pub, Full Text)

Endless customer service

- Reasonable Membership services

- Reprints availability upon request

- One step article tracking system 